\title{
SEI COMO SOU? ANÁLISE DOS PROCESSOS METACOGNITIVOS UTILIZADOS PELOS ESTUDANTES EM SITUAÇÕES DE ATIVIDADES ESCOLARES
}

\author{
Cleci Teresinha Werner Rosa* \\ Cassia de Andrade Gomes Ribeiro** \\ Alvaro Becker da Rosa ${ }^{* * *}$
}

\begin{abstract}
Resumo: O presente trabalho tem por objetivo descrever um estudo sobre as formas como estudantes do ensino médio identificam recorrer aos seus processos metacognitivos durante a realização de atividades de aprendizagem, bem como confrontá-las com as manifestações detectadas por observadores externos em duas situações distintas. Para isso, recorre à aplicação de um questionário metacognitivo e, a partir dele, seleciona um grupo de estudantes que são analisados durante duas atividades. Os alunos participantes constituem dois grupos distintos, os que declaram recorrer aos processos de pensamento metacognitivo e os que admitem ter dificuldades para isso. Dos resultados se pode inferir que tais grupos não se mantêm distintos quando investigados frente aos novos instrumentos de pesquisa. Com isso, conclui-se que a amostra investigada apresenta dificuldades para identificar seus processos metacognitivos.
\end{abstract}

Palavras-Chave: Pensamento metacognitivo. Autoimagem percebida. Tarefas de aprendizagem escolar.

\section{KNOW WHAT AM I? ANALYSIS OF THE METACOGNITIVE PROCEDURES USED BY STUDENTS IN SCHOOL ACTIVITIES}

\begin{abstract}
The present study aims to analyze how high school students identify the use of their metacognitive processes during performance of learning activities, as well to confront them with the manifestations detected by external observers in two different situations. To do this, it uses a metacognitive questionnaire and, from it, selects a group of students that are analyzed during two activities. Participating students constitute two distinct groups, those who declare resort processes of metacognitive thinking and those who admit to having difficulties. The results indicate that groups do not remain distinct when investigated in relation to the new research instruments. With this, it is concluded that the investigated sample presents difficulties to identify its metacognitive processes.

Keywords: Metacognitive thinking. Perceived self-image. Learning tasks.
\end{abstract}

Submissão 06-08-18 Aceite 18-08-19

\section{INTRODUÇÃO}

A metacognição encontra-se associada a uma forma de pensamento que possibilita aos sujeitos um autoconhecimento de suas características pessoais, tanto em termos dos conteúdos específicos de uma determinada área do conhecimento como do modo de agir para alcançar os seus objetivos. De acordo com Flavell (1976), o pensamento metacognitivo que se encontra vinculado à metacognição corresponde à ativação de mecanismos mentais que possibilitam ao próprio sujeito refletir e identificar os caminhos que o levaram a pensar ou agir de determinada maneira, permitindo

\footnotetext{
* Professora e pesquisadora em Ensino de Física, Doutora em Educação Científica e Tecnológica, Docente do Programa de Pós-Graduação em Ensino de Ciências e Matemática, Docente do Programa de Pós-Graduação em Educação.

** Graduada em Física-L, Mestranda em Ensino de Ciências e Matemática na Universidade de Passo Fundo.

**** Engenheiro Mecânico, Mestre em Ciências, Professor do Curso de Física - L da Universidade de Passo Fundo.
} 
regular e controlar suas ações em prol de alcançar êxito em seus objetivos. Em outras palavras, é um pensar sobre o pensar, ou a cognição da cognição.

Com base nesse entendimento, o presente trabalho analisou como os estudantes recorrem a essa forma de pensamento durante a realização de suas aprendizagens. Para tanto, apoia-se nos resultados de uma investigação desenvolvida por Rosa, Santos e Ribeiro (2017), que teve como participantes 624 estudantes do ensino médio e avaliou o uso do pensamento metacognitivo durante a realização de atividades escolares. O estudo foi guiado por um questionário metacognitivo composto de 25 itens, elaborado e validado na própria investigação. Nela, por meio de uma escala Likert, os alunos inferiram sobre seu modo de proceder/pensar diante das tarefas propostas no contexto escolar. O foco estava em identificar como eles se percebiam em relação ao uso do pensamento metacognitivo, ou seja, em identificar a imagem autopercebida por esses sujeitos. Como resultado, a pesquisa revelou que, a cada dez alunos investigados, quatro declararam recorrer ao uso do pensamento metacognitivo em termos da identificação de características pessoais, da tarefa e da estratégia a ser utilizada; e, a cada dez, cinco inferiram que, de forma espontânea, sem explicitação do professor, planejam como realizar suas atividades, monitorando a execução, avaliando constantemente se estão no caminho certo para atingir os objetivos traçados e redirecionando-os quando necessário.

Portanto, frente às categorias investigadas, praticamente metade dos estudantes afirmou recorrer a seus pensamentos de natureza metacognitiva. Embora aponte para a necessidade de aumentar esse número, o que pode ser efetivado por práticas pedagógicas orientadas para isso (MONEREO, 2001), esse resultado revela índices distantes de outros indicados na literatura. É o caso, por exemplo, dos achados de Schraw e Dennison (1994), Rosa e Pinho-Alves (2012) e Jaramillo e Osses (2012), que mostram resultados bem aquém dos encontrados no estudo mencionado.

O confronto desses resultados suscitou a dúvida em relação ao modo como os alunos se percebem e se de fato são conscientes da maneira como executam suas atividades. Em outras palavras, o presente estudo parte da seguinte questão de pesquisa: qual o grau de consciência dos alunos sobre a forma como pensam e executam tarefas relacionadas à aprendizagem?

Diante disso, o objetivo do presente estudo situa-se em analisar o modo como os alunos julgam utilizar seu pensamento de natureza metacognitiva e o modo como a observação externa infere que eles o utilizam. A hipótese é que muitos estudantes 
mencionam realizar determinadas ações de pensamento quando, na verdade, apresentam dificuldades/limitações para isso. Ou seja, relatam ser ou não metacognitivos, quando suas ações podem evidenciar situações contrárias aos seus relatos.

Identificar se os alunos têm ou não conhecimentos sobre o modo como agem e se isso condiz com um pensamento metacognitivo é importante porque o desconhecimento sobre si mesmo pode levar a dificuldades de aprendizagem, especialmente em termos de uma aprendizagem autorregulada (SCHUNK; ZIMMERMAN, 2003). Um aluno que aprende dessa maneira controla sua conduta e decide os passos que lhe permitem superar dificuldades. Assim, a tomada de consciência do aluno sobre sua forma de ser enquanto sujeito aprendiz potencializa a aprendizagem (PORTILHO, 2006).

Para responder ao questionamento apresentado e atingir o objetivo do estudo, procede-se à realização de uma pesquisa com a aplicação de três instrumentos, assim identificados: questionário metacognitivo, detecção de obstáculos na leitura de textos científicos e estrutura organizacional frente à resolução de situações-problema matemáticos. Os resultados são analisados à luz da literatura especializada e com base no entendimento e nas características do construto da metacognição.

Na continuidade, apresenta-se a discussão teórica que embasa este estudo, e, na sequência, são expostos os resultados e a sua análise.

\section{REFERENCIAL TEÓRICO}

Para apoiar as discussões que seguem, é necessário discorrer sobre o entendimento de metacognição adotado neste estudo, bem como sobre a importância do uso do pensamento metacognitivo como forma de potencializar e qualificar a aprendizagem. Em razão da polissemia do termo "metacognição" e da falta de um referencial teórico consensual na literatura a esse respeito, faz-se pertinente identificar o conceito em estudos que o envolvem (ZOHAR; BARZILAI, 2013). Nesse sentido, e considerando as produções teóricas no campo da educação científica, destaca-se que o entendimento adotado é o apresentado pelo pioneiro nas pesquisas envolvendo metacognição, John Hurley Flavell e seus colaboradores, acrescido das inferências de Ann Brown. Tal compreensão foi assim sintetizada por Rosa (2011, p. 57, destaque da autora):

Metacognição é o conhecimento que o sujeito tem sobre seu conhecimento e a capacidade de regulação dada aos processos executivos, somada ao controle e à orquestração desses mecanismos. 
Nesse sentido, o conceito compreende duas componentes: o conhecimento do conhecimento e o controle executivo e autorregulador.

De acordo com a autora, a definição é a clássica de Flavell, sendo diferenciada no detalhamento das componentes que estruturam esse conceito. O conhecimento do conhecimento ou conhecimento metacognitivo vincula-se à tomada de consciência dos sujeitos sobre seus próprios conhecimentos. Esses estariam vinculados às características, convicções, crenças que o sujeito tem de si mesmo em relação à sua cognição, em relação a ela em comparação com o outro, em relação às tarefas apresentadas e em relação às estratégias em ação.

O controle executivo e autorregulador, por sua vez, vincula-se às habilidades metacognitivas e é estruturado a partir de elementos como a planificação, a monitoração e a avaliação. Ao descrever esses elementos e sua influência no desenvolvimento das habilidades, Rosa (2011) menciona que eles são responsáveis pela ação e, portanto, estão organizados de modo a possibilitarem ao sujeito alcançar os seus objetivos de natureza cognitiva. Para Veenman (2011), trata-se de habilidades e processos utilizados pelos sujeitos para orientar, monitorar, controlar e regular a cognição e a aprendizagem.

Nessa linha, pode-se afirmar que as habilidades metacognitivas, assim como os conhecimentos metacognitivos mencionados anteriormente se mostram importantes em situações que envolvem a realização de tarefas como as escolares. A tomada de consciência do que eu preciso fazer, do que eu sei, de como eu sou, somada ao planejamento, à monitoração e à avaliação, constitui o cerne de um pensamento de natureza metacognitiva. Tais elementos foram os investigados no estudo de Rosa, Santos e Ribeiro (2017) e são retomados aqui. Por conta do desconhecimento que os sujeitos têm sobre si mesmos e sua relação com a aprendizagem, tema aventado no questionamento desta investigação, destaca-se o estudo de Gilovich (1991) sobre a dissonância cognitiva e o papel negativo que ela exerce sobre a aprendizagem. Segundo o autor, os erros de aprendizagem estão vinculados à falta de conhecimento que os alunos têm sobre o que sabem, sobre a forma como aprendem e sobre o emprego cognitivo que precisam fazer para resolver uma tarefa.

Essa falta de gerenciamento sobre o seu modo de pensar e a estrutura necessária para resolver situações de aprendizagem também é destacada por Portilho (2006), que chama a atenção para a necessidade de que cada sujeito conheça o seu estilo de aprendizagem e as ações que é capaz de executar para aprender. Enfim, o desconhecimento provoca uma variedade de empreendimentos cognitivos 
que prejudicam o aluno, como o erro, as incertezas, a insegurança, entre outros. Tal identificação deveria ser considerada pelos professores no momento de planejar suas atividades pedagógicas, ressaltando a necessidade de incluir momentos de evocação do pensamento metacognitivos.

\section{DESCRIÇÃO METODOLÓGICA}

A pesquisa é de abordagem qualitativa e está pautada pelas discussões de Triviños (1994), ao inferir que esse tipo de pesquisa prioriza a interpretação e discussão dos dados de forma a buscar seu significado, tendo como base a percepção do fenômeno dentro do seu contexto. A descrição qualitativa procura captar não só a aparência do fenômeno, mas também suas essências, visando explicar sua origem, relações, mudanças, e tenta intuir possíveis consequências.

Além disso, a pesquisa é identificada como um estudo de caso. De acordo com Gil (2002), essa opção se mostra adequada quando não se tem como meta proporcionar o conhecimento preciso de determinado grupo, mas sim dar uma visão ampla do problema ou identificar fatores que o influenciam ou são influenciados por ele. Yin (2015), por sua vez, destaca que o estudo de caso não busca alcançar generalizações universais, mas generalizações analíticas voltadas para a ampliação e generalização de teorias. Segundo o autor, a vantagem de realizar esse tipo de estudo está na sua capacidade de lidar com uma grande variedade de fontes de evidências, tais como documentos, artefatos, entrevistas e observações.

Para a coleta dos dados, o estudo recorreu a uma investigação em três etapas. A primeira, destinada a selecionar os sujeitos que integraram a segunda, envolveu a aplicação do questionário metacognitivo utilizado no estudo de Rosa, Santos e Ribeiro (2017) a uma amostra de 46 estudantes da terceira série do ensino médio de uma escola pública na cidade de Nova Bassano, RS. Os alunos, que participaram por livre adesão, responderam ao questionário metacognitivo contendo 25 itens. Na sequência, e a partir dos resultados obtidos com o questionário, foram selecionados dez sujeitos, para participar da segunda etapa e da qual trata esse artigo. Para a seleção desses dez sujeitos tomou-se como critérios (i) aqueles que haviam respondido os itens do questionário inferindo realizar ações identificadas com o uso do pensamento metacognitivo; (ii) e, aquele que, ao contrário, mencionaram recorrer pouco a essa forma de pensamento. A necessidade de selecionar dois grupos de sujeitos decorre 
do objetivo da pesquisa, vinculado a analisar diferenças de comportamento nas ações dos alunos que integram esses distintos grupos.

A limitação de dez sujeitos, cinco em cada um dos grupos, teve como justificativa o procedimento adotado para a coleta de dados. Para essa segunda etapa, os dez alunos selecionados realizaram duas atividades: leitura de dois textos de natureza científica com registro escrito dos questionamentos na forma de obstáculos de compreensão; e resolução de três exercícios na forma de problemas envolvendo conteúdos de matemática com descrição oral dos procedimentos. Nessa última, foi utilizado o protocolo de "pensar em voz alta" ou "entrevistas clínicas do tipo Think Aloud", que permite analisar as manifestações verbais do aluno por meio da gravação individual durante a realização das atividades propostas. Para isso, os sujeitos foram levados a resolver as situações-problema apresentadas, narrando seus passos e pensamentos em voz alta. Tais manifestações foram livres e gravadas em áudio.

Os diferentes instrumentos utilizados levaram à discussão dos dados por meio da triangulação metodológica. Conforme Minayo (2000, p. 48), as pesquisas qualitativas podem ser compreendidas como "aquelas capazes de incorporar a questão do significado e da intencionalidade como inerentes aos atos, às relações, e às estruturas sociais, sendo essas últimas tomadas tanto no seu advento quanto na sua transformação, como construções humanas significativas". Nesse sentido, a triangulação metodológica representa uma técnica que nos permite efetivar um olhar múltiplo e diferente do mesmo fenômeno em estudo, de modo a capturar dos sujeitos envolvidos uma relação maior que as identificadas na leitura dos resultados individuais de cada instrumento.

De acordo com Vergara (2004), a triangulação pode ser tomada de duas perspectivas: como estratégia que contribui para a validade de uma pesquisa e como alternativa para a obtenção de novos conhecimentos, por meio de pontos de vista distintos do ofertado pelos instrumentos individualizados. Em uma pesquisa do tipo “estudo de caso", como o apresentado nesta investigação, Yin (2015) orienta que a triangulação é o mais conveniente, uma vez que permite ao pesquisador abordar uma variedade de aspectos que a coleta de dados individualizada não permite. Nesse sentido, a triangulação metodológica da presente pesquisa apoiou-se nos diferentes instrumentos utilizados e que buscaram discutir o mesmo fenômeno, ou seja, o principal objetivo da integração desses diferentes instrumentos e métodos de pesquisa foi a convergência de resultados de investigação. 


\section{RESULTADOS}

Os resultados obtidos no estudo são apresentados e discutidos de acordo com os instrumentos utilizados, e apresentam-se ao final as inferências envolvendo a triangulação metodológica. A primeira etapa envolveu a aplicação de um questionário a 46 estudantes de uma turma de terceiro ano do ensino médio, voltado a identificação do uso dos processos metacognitivos durante a realização das atividades escolares. Esse questionário tomou por referência o desenvolvido por Rosa, Santos e Ribeiro (2017) e foi estruturado em duas grandes categorias: conhecimento do conhecimento; e, controle executivo e autorregulador. Para cada item das categorias os estudantes deveriam assinalar uma alternativa indicada pelas opções: "nunca", "poucas vezes", "às vezes", "muitas vezes" e "sempre". Tais alternativas correspondiam a ações que estavam descritas no item e que representavam características do uso do pensamento metacognitivo. Como exemplo menciona-se o item 13 que inferia a seguinte ação: "Quando começa uma tarefa, pensa em quais objetivos pretende alcançar". Ao ler essa assertiva o estudante deveria avaliar e assinalar uma das cinco alternativas mencionadas anteriormente. O questionário estava integralizado pro 25 itens assim distribuídos: 13 na categoria conhecimento do conhecimento e 12 relacionados a categoria controle executivo e autorregulador.

No estudo realizado com os 46 estudantes, foi possível identificar os que relatavam recorrer ao pensamento metacognitivo e os que mencionavam não usufrui desta forma de pensamento. Tal identificação foi estabelecida a partir dos percentuais assinalados para as alternativas "nunca" e "poucas vezes" e para "muitas vezes" e "sempre", indicando, respectivamente, os estudantes com dificuldades de utilização do pensamento metacognitivo (Grupo denominado de "G1") e os estudantes que apresentam facilidade da evocação desse pensamento (Grupo denominado de “G2”). Os resultados obtidos indicam que cerca de $20 \%$ dos estudantes se consideram metacognitivos em se tratando do conhecimento do conhecimento e, aproximadamente, $25 \%$ em termos do controle executivo e autorregulador. Já para os que não se declaram metacognitivos, os índices são de, aproximadamente, $20 \%$ para a primeira categoria e cerca de $10 \%$ para a segunda.

Esses resultados representam um índice elevado em se considerando resultados de outras investigações, como as que aplicam o Metacognitive Awareness Inventory 
$(\mathrm{MAI})^{1}$ ou o desenvolvido por Jaramillo e Osses $(2012)^{2}$, por exemplo. Embora realizados com objetivos distintos dos aqui traçados, esses testes mencionam as dificuldades dos alunos em recorrer a seus pensamentos metacognitivos e, a partir disso, discutem a relação com o rendimento acadêmico e a importância de os professores considerarem a inclusão de momentos explícitos de evocação do pensamento metacognitivo em sua prática pedagógica (MONEREO, 2001; AKIN; ABACI; CETIN, 2007; YOUNG; FRY, 2008; VEENMAN, 2011, THOMAS, 2012).

No caso do questionário desenvolvido e cujo referencial está próximo do utilizado nos testes mencionados, percebeu-se que os estudantes se mostraram mais identificados com o uso do pensamento metacognitivos o que levou a ampliar os instrumentos de investigação e avaliar a forma como eles utilizam esse pensamento durante a realização das tarefas escolares, conforme mencionado na introdução deste texto.

A partir dos resultados selecionou-se por livre adesão dez estudantes para participar das atividades integrantes da segunda etapa do estudo, sendo cinco integrantes do grupo que declarou utilizar o pensamento metacognitivo e cinco do grupo que relatou ter dificuldades para isso. O primeiro grupo foi identificado por "G1" e o segundo por “G2”, seguindo o apresentado anteriormente.

Os estudantes de ambos os grupos nessa segunda etapa, foram submetidos a duas atividades: leitura de dois textos científicos em que foram introduzidos cinco obstáculos de compreensão; e, realização de três situações-problema envolvendo cálculos matemáticos. No caso dos textos, o objetivo foi avaliar os obstáculos encontrados pelos estudantes, e no caso da resolução das situações-problema, avaliar como processavam mentalmente a execução dessa atividade. Ambos os instrumentos oferecem condições de avaliar o uso do pensamento metacognitivo, uma vez que exigem monitoramento e controle das ações.

No caso dos textos científicos (Apêndice A), a solicitação foi que, ao fazerem a leitura, os alunos indicassem, por meio de registros escritos, os obstáculos encontrados na compreensão, classificando, ainda, o grau de dificuldade de cada texto. Para isso, foram-lhes apresentados os seguintes comandos: “1) Ler os dois textos que

\footnotetext{
${ }^{1}$ O Metacognitive Awareness Inventory (MAI), elaborado por Gregory Schraw e Rayne Sperling Dennison (1994), proporciona a investigação do uso do pensamento metacognitivo de estudantes pautado em situações de aprendizagem. O teste, composto por 52 itens, é estruturado dentro das duas componentes metacognitivas indicadas por Flavell (1979): conhecimento metacognitivo e habilidades metacognitivas, cada qual subdividida em elementos estruturados, no caso da primeira componente, por Flavell e Wellmann (1977), e no caso da segunda, pelos próprios autores do teste.

${ }^{2}$ Esse instrumento foi concebido para medir o uso da metacognição em termos das componentes conhecimento e experiências metacognitivas e capacidade de autorregulação. $\mathrm{O}$ instrumento conta com 33 itens estruturados na forma de uma escala Likert (JARAMILLO; OSSES, 2012).
} 
apresentamos a seguir e registrar as dificuldades de compreensão de duas maneiras: sublinhando a parte que não compreende e escrevendo ao lado por que não compreende; 2) Pontue o grau de dificuldade do texto lido utilizando uma escala de 1 a 5, assim identificada: 1 (Muito difícil), 2 (Difícil), 3 (Intermediário), 4 (Fácil) e 5 (Muito Fácil)".

No primeiro texto ("Segurando a vida"), foram introduzidos três obstáculos ou inconsistências conceituais, e no segundo texto ("Eletricidade estática"), dois. O nível de compreensão fornece uma ideia para identificar se os alunos consideram os textos cognitivamente adequados à sua capacidade de compreender. Vale lembrar que o grupo estava composto por estudantes do terceiro ano e, portanto, tais conteúdos já haviam sido abordados na escola.

No caso do primeiro grupo (G1), formado pelos estudantes que haviam se declarado evocadores do pensamento metacognitivo, o número médio de obstáculos identificados no texto 1 foi 2 e no texto 2 , de 1 . No segundo grupo (G2), formado pelos sujeitos que declaradamente não recorrem aos pensamentos metacognitivos diante das tarefas escolares, o índice de detecção dos obstáculos foi de 1,8 para o primeiro texto e de 1 para o segundo.

O Quadro 1 apresenta exemplos dos obstáculos mencionados pelos alunos.

QUADRO 1 - Registros dos obstáculos de compreensão

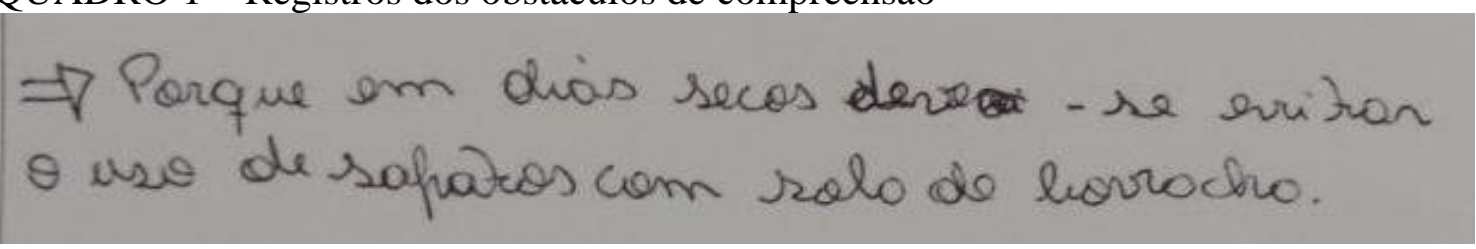

- passageino ná esta \& completamente pro. tegido dentro do capio, mesmo que estiver com sinto de seguranģo ele conheró pe. Rigo. 


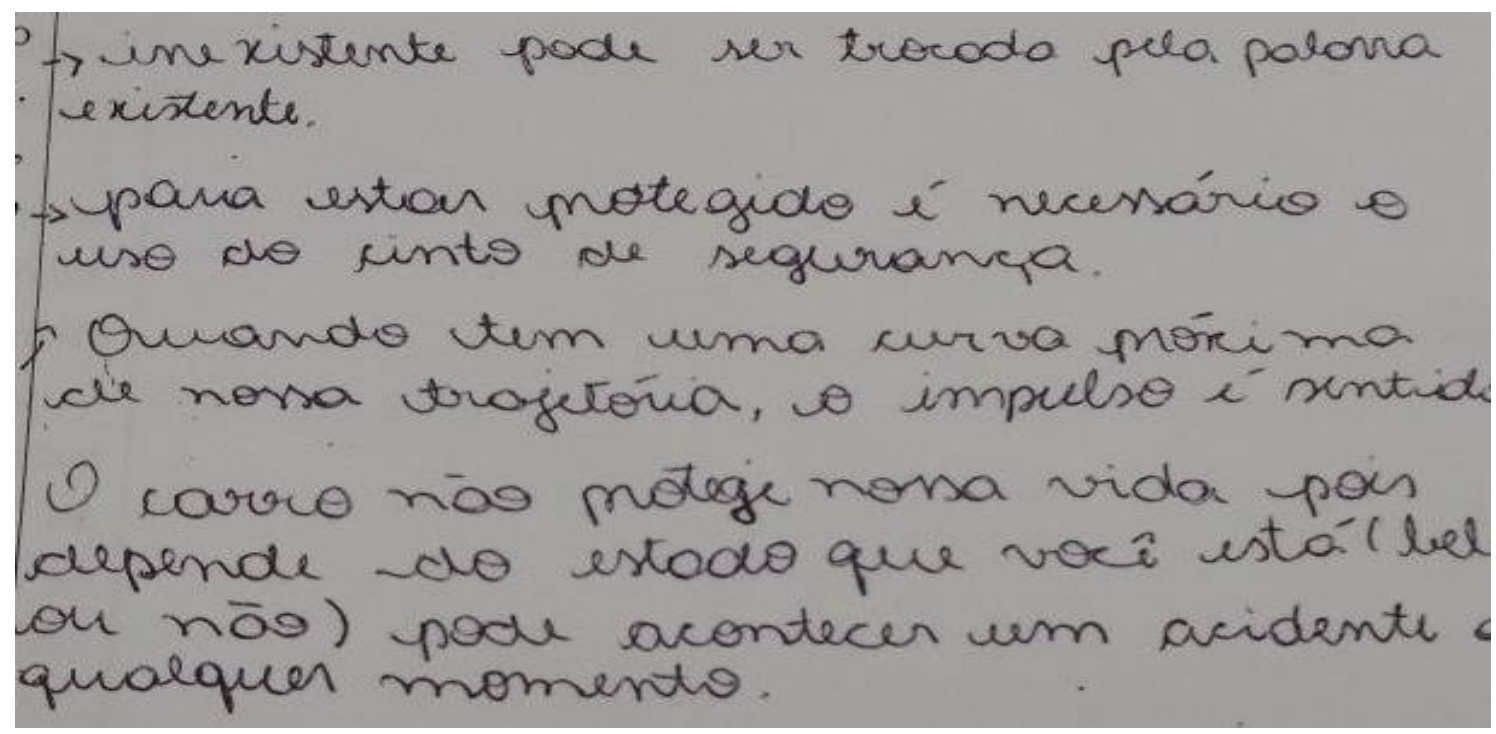

FONTE: dados da pesquisa, 2017.

Em termos dos escores para o grau de dificuldades, tem-se que, para o G1, o primeiro texto apresentou uma média de 4,4 e o segundo texto, de 3,6; já para o G2, o texto 1 obteve uma média de 3,8 , e o texto 2 , de 3,4. Tais resultados indicam poucas diferenças entre os dois grupos e, portanto, revelam que os estudantes investigados não são capazes de reconhecerem-se como metacognitivos ou não.

O exposto pauta-se pela identificação dos obstáculos, uma vez que são facilmente identificáveis e, numa leitura atenta, quem pensa e reflete sobre o que está lendo deveria ser capaz de detectá-los. Por exemplo, um estudante que recorre ao pensamento metacognitivo rapidamente deveria se dar conta de que na frase a seguir há uma incoerência conceitual: "No caso de uma viagem nas estradas brasileiras, o limite de $80 \mathrm{~km} / \mathrm{h}$ imposto para a maioria delas deve ser respeitado, caso contrário, corremos o risco de, em virtude da aceleração gravitacional variar, sofrermos vertigens e perdermos o controle do carro" (fragmentos do texto 1). Dessa forma, esse estudante deveria questionar: por que a aceleração gravitacional? O que ela tem a ver com a velocidade limite de $80 \mathrm{~km} / \mathrm{h}$ ? Nesse caso, estudantes de ambos os grupos não sublinharam, nem mesmo questionaram o mencionado.

Em outra passagem, afirmou-se que "Toda vez que alguém aproxima sua mão de um objeto metálico que está ligado ao solo, uma pequena faísca poderá saltar desse objeto". Nesse caso, em ambos os grupos, os alunos questionaram o fato de que pode ocorrer faíscas com qualquer objeto metálico. E assim sucessivamente, em ambos os textos, observou-se que alunos dos dois grupos identificaram (ou não) obstáculos de compreensão. Desse modo, não foi possível classificar os dois grupos em função do número de obstáculos identificados. O mesmo ocorreu com o grau de dificuldades 
apontado pelos alunos, uma vez que a diferença entre os dois grupos nas pontuações médias foi muito pequena, conforme já mencionado.

O fato da diferença ser sutil entre os dois grupos quanto aos obstáculos de compreensão, se afasta dos estudos de Van Den Broek et al. (2001), Otero, Caldeira e Gomes (2004), Otero (2009), Rosa e Otero (2015), entre outros, os quais mencionam que alunos que recorrem ao pensamento metacognitivo são capazes de monitorar melhor a sua compreensão. Dessa forma, o resultado apresentado por meio deste primeiro instrumento revela dificuldade em estabelecer uma relação entre a capacidade de identificar obstáculos de compreensão e o uso do pensamento metacognitivo, pelo menos em uma amostra com poucos sujeitos.

$\mathrm{Na}$ continuidade do estudo e com intuito de ampliar os dados coletados, foram apresentadas aos sujeitos dos dois grupos três situações-problema que eles deveriam resolver expressando oralmente o procedimento utilizado. Nessa etapa, recorreu-se ao protocolo de "pensar em voz alta" ou "entrevistas clínicas" do tipo Think Aloud. Essa estratégia possibilita analisar, por meio de gravação, as manifestações verbais do aluno durante a realização da atividade proposta. Para isso, foram realizadas sessões individuais com a duração de 45 minutos a 1 hora e 20 minutos cada. Todo o material foi gravado em áudio e posteriormente transcrito.

No cabeçalho da folha com as situações-problema (Apêndice B), estava especificada a seguinte instrução: "Resolva as questões apresentadas de modo a explicitar oralmente os passos realizados". Para analisar os resultados dessa etapa, adotou-se a estratégia de contabilizar passagens que podem ser relacionadas com manifestações de evocação do pensamento metacognitivo, seguindo o apresentado por Flavell (1976) e Brown (1987) e descrito nos estudos de Rosa (2011), como integrante das componentes conhecimento do conhecimento e controle executivo e autorregulador.

Após analisar detalhadamente o material relativo às transcrições, foi possível identificar o número de manifestações metacognitivas em cada grupo, expressas na Tabela

TABELA 1 - Manifestações metacognitivas na resolução de situações-problema

\begin{tabular}{|l|c|c|}
\hline & G1 & G2 \\
\hline Conhecimento do conhecimento & 13 & 18 \\
\hline Controle executivo e autorregulador & 12 & 6 \\
\hline
\end{tabular}

FONTE: dados da pesquisa, 2017.

Como resultado dessa etapa, os estudantes de ambos os grupos apresentaram inferências equivalentes. Entretanto, os do G2 evidenciaram mais inferências do tipo 
conhecimento de si mesmo, com relato de crenças sobre si mesmos ou sobre a atividade, em contrapartida a manifestações associadas ao controle executivo e autorregulador.

As manifestações metacognitivas utilizadas pelos estudantes foram do tipo: "Eu estou acostumada a resolver com calculadora, [...] agora é só calculadora que a gente ocupa, esse tipo de continha a gente não viu mais vezes"; "Não sou boa em matemática"; "Nunca gostei de resolver esses probleminhas"; "[...] eu faço sempre mais pela lógica do que... ai não sei"; "Na verdade estou tentando entender melhor o problema"; "Na verdade eu sou péssima em matemática, não sei nem como faria"; "Está tudo errado isso"; "Não sei nem o que eu estou fazendo"; "Bem, primeiro vou dividir 430 por 9 e depois vou ver se sobra algo, e aí tenho que pensar como fazer, porque não pode sobrar nem um aluno"; "Vou dividir a quantidade de livros pelo número de pacotes e acho que vou encontrar quantos livros vai em cada pacote"; "Acho que se eu fizer assim vou conseguir resolver"; "Fiz uns cálculos e acho que não entendi direito como fazer".

Essas manifestações dos estudantes dos dois grupos durante a resolução das três situações-problema sugerem que, a exemplo do identificado na detecção dos obstáculos de compreensão na leitura dos textos científicos, não há uma correlação entre os declaradamente metacognitivos e os que julgam apresentar dificuldades para evocar pensamentos dessa natureza. Entretanto, observou-se que os estudantes do G2 demoraram mais para realizar as atividades (em média 1h11 min) em comparação com os do G1 (em média 53 minutos) e que os do primeiro grupo manifestaram mais destrezas matemáticas que os do segundo, levantando poucas dúvidas durante a resolução de problemas. Tal inferência aponta para a possibilidade de uma nova avaliação que inclua os rendimentos acadêmicos.

Frente aos resultados encontrados pela utilização dos três instrumentos, ao recorrer à técnica da triangulação metodológica, identificaram-se situações de conflito entre o respondido pelo aluno no questionário e o detectado pelos dois instrumentos adotados na segunda fase do estudo. A seguir são exemplificadas essas situações, cuja descrição ocorre considerando as duas componentes metacognitivas elencadas por Flavell (1976): conhecimento metacognitivo e controle executivo e autorregulador.

Em termos do conhecimento do conhecimento, os registros do questionário respondido pelos alunos do G1 indicam que aproximadamente $30 \%$ deles recorreram a essa forma de pensamento, enquanto $25 \%$ dos respondentes do G2 assinalaram 
não utilizá-la. Os resultados obtidos no que refere aos obstáculos evidenciam que ambos os grupos tiveram dificuldades para identificá-los, pois, dos sete obstáculos inferidos intencionalmente nos dois textos, a média do G1 foi de três obstáculos e do G2, de 2,8. Por fim, na resolução de situações-problema, os alunos do G1 manifestaram menos inferências metacognitivas que os do G2 (13 para o G1 e 18 para o G2).

Esses resultados demonstram haver uma contradição entre o anunciado pelos estudantes e o registrado pelos pesquisadores na segunda parte do trabalho. Os mesmos alunos que, na primeira etapa, disseram realizar ações como procurar compreender a tarefa para depois iniciar seu procedimento, ou, para entender melhor, ler e reler a tarefa, na segunda parte, mostraram dificuldades para isso. Embora essas ações tenham sido identificadas, não o foram na intensidade que os alunos responderam realizá-las (muitas vezes e sempre). Da mesma forma, os do G2 registraram não realizar as ações como as mencionadas, mas aos olhos dos pesquisadores, por vezes, alguns deles as realizaram.

Da mesma forma, observa-se essa incoerência nos resultados ao analisar a componente do controle executivo e autorregulador. Nela, os registros do questionário revelam que $40 \%$ dos alunos do G1 consideram que realizam essa ação; em contrapartida, $20 \%$ dos alunos que integram o G2 revelam que não a fazem. Na análise dos textos, os resultados foram os já anunciados, uma vez que não foram classificados em termos das componentes metacognitivas, ou seja, os dois grupos tiveram dificuldades para identificar obstáculos. Por sua vez, os resultados obtidos na etapa de resolução de situações-problemas revelam que, ao contrário da componente anterior, nesta os alunos do G1 realizaram mais ações do tipo metacognitivas que os do G2 (12 para o G1 e 6 para o G2). Avaliando e confrontando os achados do questionário com os obstáculos encontrados na leitura dos textos e as manifestações metacognitivas na resolução das situações-problema, percebe-se que nem os alunos do G1, nem os do G2 foram condizentes com seus registros.

Disso, tem-se que, por não haver diferenças significativas entre os dois grupos na segunda parte do estudo, pelo menos não na mesma proporção indicada na primeira, os estudantes apresentam pouco conhecimento de si ou pensam agir de uma forma quando na realidade agem de outra. Essa falta de consciência dos estudantes sobre como eles são enquanto sujeitos aprendizes, sobre como se estruturam para atingir seus objetivos, ou, ainda, a falta de uma imagem autopercebida condizente com suas ações podem refletir em dificuldades de aprendizagem. 
Portilho (2006, p. 57), relatando a importância para a aprendizagem de que as pessoas aprendam a se conhecer, destaca que:

Ao conhecer-se cada vez um pouco mais, a pessoa abre possibilidades de analisar as exigências próprias da tarefa e relaciona-as com a realidade que se apresenta. Pode refletir sobre a informação, averiguar o objetivo da atividade que tem a realizar, observar o que existe de novidade e familiar e detectar os níveis de dificuldade, tornando-se assim autônoma diante de suas aprendizagens.

A mesma situação é enfatizada por Vaz-Rebelo et al. (2016), ao defenderem que a importância da análise da ignorância consciente do processo de aprendizagem escolar se justifica inicialmente pelo papel que a consciência do desconhecimento e da incompreensão expressa na elaboração de novos problemas de pesquisa. Em segundo lugar, os autores mencionam que ser consciente da própria ignorância é uma condição essencial para a autorregulação do processo de aquisição de conhecimentos e para a compreensão da ciência, "de forma que el alumno progrese evaluando lo que le falta por recorrer desde su estado actual hasta la meta de conocimiento y comprensión que debe ser alcanzada" (MONTALVO; GONZÁLEZ-TORRES, 2004, p. 96).

Enfim, são várias as razões para que os estudantes se tornem conscientes de seus processos de aprendizagem e construam uma autoimagem condizente com suas ações. E foi nesse sentido que o estudo focou sua análise apoiado pelos instrumentos e pelas discussões apresentadas. Com relação aos instrumentos utilizados, vale registrar que um dos problemas mais difíceis dos estudos relacionados à metacognição, e que tem sido um limitador para ampliar os resultados especificamente no campo empírico, é a forma como os dados podem ser coletados. Essa problemática, já anunciada por White (1990) no início da década de 1990, persiste até hoje, uma vez que, de acordo com o autor, a metacognição implica pensamento, e isso é complexo de verificar. Dentre as alternativas apontadas está o uso de questionário e dos protocolos de entrevista como os estruturados para o presente estudo. Além disso, infere o autor a possibilidade de utilizar registros em papel, como optaram Rosa e Otero (2015), e as fichas de observações envolvendo manifestações verbais e/ou físicas como as adotadas por Rosa (2011).

\section{CONSIDERAÇÕES FINAIS}

A título de conclusão, retoma-se que o presente estudo se ocupou de analisar a relação entre o modo como os estudantes percebem suas ações e pensamentos frente 
aos processos metacognitivos e a maneira como eles são percebidos por um observador externo. Nesse contexto, apontou-se para a hipótese de que os estudantes podem ter uma imagem equivocada de si mesmos ou ter dificuldades para reconhecer sua forma de pensamento especialmente em termos do uso do pensamento metacognitivo.

Tal conclusão foi obtida a partir dos resultados encontrados e que confirmam a hipótese inicial do estudo. No caso dos estudantes do G1, que se declararam metacognitivos, observou-se haver dificuldades para detectar obstáculos simples de compreensão ou para evocar pensamentos metacognitivos durante a realização de problemas simples envolvendo cálculos matemáticos; em contrapartida, os que se declararam não recorrer a pensamentos de natureza metacognitiva utilizam tais recursos em ambas às situações analisadas.

Por fim, destaca-se que o estudo sinaliza para uma nova investigação envolvendo o rendimento escolar e sua relação com a imagem autopercebida dos alunos, buscando estabelecer uma conexão com os estudos de Chi e colaboradores (1982; 1989). Tal situação representa uma nova enseada na busca por ampliar os estudos em metacognição e evidenciar a sua importância como mecanismo potencializador da aprendizagem.

\section{REFERÊNCIAS}

AKIN, A.; ABACI, R.; CETIN, B. The Validity and Reliability of the Turkish Version of the Metacognitive Awareness Inventory. Educational Sciences: Theory \& Practice, v. 7, n. 2, p. 671-678, 2007.

BROWN, A. L. Metacognition, executive control, self-regulation, and other more mysterious mechanisms. In: WEINERT, F. E.; KLUWE, R. H. (Eds.). Metacognition, motivation and understanding. Hillsdale, New Jersey: Lawrence Erlbaum Associates, 1987. p. 65-116.

CHI, M. T.; GLASER, R.; REES, E. Expertise in problem solving. In: STERNBERG, R. J. (Ed.). Advances in the psychology of human intelligence. v. 1. Hilsdale, N. J.: Erlbaum, 1982.

. et al. Self-explanations: How students study and use examples in learning to solve problems. Cognitive Science, v. 13, p. 145-182, 1989.

FLAVELL, J. H. Metacognitive aspects of problem solving. In: RESNICK, L. B. (Ed.). The nature of intelligence. Hillsdale, New Jersey: Lawrence Erlbaum Associates, 1976. p. 231-236.

GIL, A. C. Como elaborar projetos de pesquisa. 4. ed. São Paulo: Atlas, 2002.

GILOVICH, T. How we know what isn't so: the fallibility of human reason in everyday life. New York: The Free Press, 1991. 
JARAMILLO, S.; OSSES, S. Validación de un Instrumento sobre Metacognición para Estudiantes de Segundo Ciclo de Educación General Básica. Estudios Pedagógicos, v. 38, n. 2, p. 117-131, 2012.

MINAYO, M. C. S. O desafio do conhecimento: pesquisa qualitativa em saúde. 7. ed. São Paulo: Hucitec, 2000.

MONEREO, C. La enseñanza estratégica: enseñar para la autonomía. In:

Ser estratégico y autónomo aprendiendo. Barcelona: Graó, 2001. p. 11-27.

OTERO, J. Question generation and anomaly detection in texts. In: HACKER, D. J.; DUNLOSKY, J.; GRAESSER, A. (Eds.). Handbook of metacognition in education. New York: Routledge, 2009. p. 47-59.

.; CALDEIRA, H.; GOMES, C. J. The influence of the length of causal chains on question asking and on the comprehensibility of scientific texts. Contemporary Educational Psychology, v. 29, n. 1, p. 50-62, 2004.

PORTILHO, E. M. L. As estratégias metacognitivas de quem aprende e de quem ensina. In: MALUF, M. I. Aprendizagem: tramas do conhecimento, do saber e da subjetividade. Petrópolis: Vozes, 2006. p. 47-59.

ROSA, C. T. W. A metacognição e as atividades experimentais no ensino de Física. 2011. Tese (Doutorado em Educação Científica e Tecnológica) - Universidade Federal de Santa Catarina, Florianópolis, Brasil.

; PINHO-ALVES, J. Evocação espontânea do pensamento metacognitivo nas aulas de Física: estabelecendo comparações com as situações cotidianas. Revista Investigações em Ensino de Ciências, v. 17, n. 1, p. 7-19, 2012.

; OTERO, J. A influência da autoridade epistémica e da competência autopercebida no julgamento de estudantes sobre a compreensão da ciência. In ENCONTRO NACIONAL DE EDUCAÇÃO EM CIÊNCIAS, 16, 2015, Lisboa, Portugal. Anais... Lisboa, Instituto de Educação da Universidade de Lisboa, 2015. p. 423-427.

; SANTOS, A. C.; RIBEIRO, C. Pensamento metacognitivo em estudantes do ensino médio: elaboração, validação e aplicação de um instrumento. In: CONGRESSO INTERNACIONAL DE EDUCAÇÃO CIENTÍFICA E TECNOLÓGICA, 4, 2017, Santo Ângelo, Anais... Santo Ângelo, URI, 2017.

SCHRAW, G.; DENNISON, R. S. Assessing metacognitive awareness. Contemporary Educational Psychology, v. 19, n. 4, p. 460-475, 1994.

SCHUNK, D. H.; ZIMMERMAN, B. J. Self-regulation and learning. Handbook of Psychology, 2003.

THOMAS, G. P. Metacognition in science education: past, present and future considerations. In: FRASER, B. J.; TOBIN, K.; MCROBBIE, C. J. (Eds.). Second international handbook of science education. Dordrecht: Springer, 2012. v. 24. p. 131-144.

TRIVIÑOS, A. N. S. Introdução à pesquisa em ciências sociais: a pesquisa qualitativa em educação. 4. ed. São Paulo: Atlas, 1994.

VAN DEN BROEK, P. et al. The effects of readers' goals on inference generation and memory for texts. Memory \& Cognition, v. 29, n. 8, p. 1081-1087, 2001.

VAZ-REBELO, P. et al. Ignorancia consciente en el aprendizaje de las ciencias II: factores que influyen en lo que los alumnos saben que no saben. Enseñanza de las Ciencias:

Revista de Investigación y Experiencias Didácticas, v. 34, n. 1, p. 91-105, 2016. 
VEENMAN, M. V. J. Learning to self-monitor and self-regulate. In: MAYER, R. E.; ALEXANDER, P. A. (Eds.). Handbook of research on learning and instruction. New York, NY: Routledge, 2011. p. 197-218.

VERGARA, S. C. Projetos e relatórios de pesquisa em administração. 5. ed. São Paulo: Atlas, 2004.

WHITE, R. T. Metacognition. In: KEEVES, J. P. (Ed.). Educational research, methodology and measurement: an international handbook. Oxford: Pergamon Press, 1990. p. 70-75.

YIN, R. K. Estudo de caso: planejamento e métodos. 5. ed. Porto Alegre: Bookman, 2015.

YOUNG, A.; FRY, J. D. Metacognitive awareness and academic achievement in college students. Journal of the Scholarship of Teaching and Learning, v. 8, n. 2, p. 1-10, 2008.

ZOHAR, A.; BARZILAI, S. A review of research on metacognition in science education: current and future directions. Studies in Science Education, v. 49, n. 2, p. 121-169, 2013. 


\section{APÊNDICE A}

O presente trabalho investiga o uso do pensamento metacognitivo como os alunos de ensino médio. Para isso solicitamos sua colaboração no sentido de realizar atentamente as atividades que seguem.

\section{PARTE I DO TESTE}

1) Ler os dois textos que apresentamos a seguir e registrar as dificuldades de compreensão de duas maneiras: sublinhando a parte que não compreende e escrevendo ao lado por que não compreende.

2) Pontue o grau de dificuldade do texto lido utilizando a escala de 1 a 5 assim identificada: 1 (Muito difícil); 2 (Difícil); 3 (Intermediário); 4 (Fácil); e 5 (Muito Fácil).

\begin{tabular}{|c|c|}
\hline Texto 1: Segurando a vida & $\begin{array}{l}\text { Registro das } \\
\text { dificuldades }\end{array}$ \\
\hline $\begin{array}{l}\text { Em um carro o perigo de um passageiro se machucar no } \\
\text { momento de uma colisão ou freada busca é praticamente } \\
\text { inexistente. Isso ocorre pelo fato de que ele, estando } \\
\text { dentro do carro, está protegido, independentemente da } \\
\text { forma como estiver dentro do veículo. Por isso é de } \\
\text { fundamental importância respeitar a sinalização sobre } \\
\text { locais em que é proibida a ultrapassagem. } \\
\text { Outra questão importante sobre a proteção que o carro } \\
\text { oferece a nossa vida é o fato de que em uma viagem estamos } \\
\text { nos deslocando com a velocidade do carro, caso estejamos } \\
\text { imóveis em relação a esse carro. Isso nos leva a, por } \\
\text { exemplo, não sofrermos os impactos do atrito do pneu do } \\
\text { carro com o solo, oferecendo mais segurança nas curvas. } \\
\text { Por fim, pode-se dizer que o carro protege nossa vida e } \\
\text { para isso é importante que ele esteja com uma velocidade } \\
\text { adequada a cada situação. No caso de uma viagem nas } \\
\text { estradas brasileiras, o limite de } 80 \mathrm{~km} / \mathrm{h} \text { imposto para a } \\
\text { maioria delas deve ser respeitado, caso contrário, } \\
\text { corremos o risco de, em virtude da aceleração } \\
\text { gravitacional variar, sofrermos vertigens e perdermos o } \\
\text { controle do carro. }\end{array}$ & \\
\hline
\end{tabular}




\begin{tabular}{|l|l|}
\hline Texto 2: Eletricidade estática & Registro das dificuldades \\
\hline Quando uma pessoa atrita a sola do sapato sobre um & \\
tapete, seu corpo pode ficar eletrizado. Toda vez que & \\
alguém aproxima sua mão de um objeto metálico que está & \\
ligado ao solo, uma pequena faísca poderá saltar desse & \\
objeto. Por isso, em dias secos deve-se evitar sapatos com & \\
solado de borracha. & \\
Há casos em que os eventuais acúmulos de eletricidade & \\
estática são extremamente perigosos, podendo resultar em & \\
faíscas perigosas. Como consequência os postos de & \\
combustível e aeroportos tomam certos cuidados na & \\
prevenção desses possíveis acidentes. Dentre os cuidados & \\
está o uso das correntes metálicas suspensas nos & \\
caminhões de abastecimento ou mesmo o seu aterramento & \\
no momento de transferir combustível para os tanques. & \\
Isso se deve ao fato de que as ondas eletromagnéticas & \\
presentes no ar podem interferir na umidade do ar, & \\
deixando-o mais propenso a emitir faíscas. & \\
\hline
\end{tabular}

$\begin{array}{llllll}\text { Grau de dificuldade: } & 1 & 2 & 3 & 4 & 5\end{array}$




\begin{abstract}
APÊNDICE B
PARTE II DO TESTE

Resolva as questões apresentadas de modo a explicitar oralmente os passos realizados.

1. Para um torneio, 430 alunos da $5^{\text {a }}$ série formarão equipes com 9 alunos. Quantas equipes serão formadas? Sobrarão alunos? Se alguns alunos ficarem de fora das equipes, como você acha que este problema pode ser resolvido?
\end{abstract}

2. Seu Manoel está tendo muita dificuldade com a divisão e pede sua ajuda. Ele precisa distribuir 750 livros em pacotes com quantidades iguais, sendo que em cada pacote cabem 5 livros. Como você faria para ajudá-lo a realizar esta divisão? O que você explicaria para ele? De que maneira?

3. Em uma cesta estão 500 maçãs, e eu preciso colocá-las em embalagens com capacidade para uma dúzia de laranjas.
a. Quantas embalagens ficarão completas?
b. Alguma embalagem ficará incompleta?
c. Se alguma embalagem ficar incompleta, quantas maçãs ficarão nela?
d. E se fossem 200 maçãs, como ficaria a distribuição? 